\section{REVIEW ARTICLE}

\title{
The use of small subunit rRNA sequences to unravel the relationships between anaerobic ciliates and their methanogen endosymbionts
}

\author{
T. Martin Embley ${ }^{1}$ and Bland J. Finlay ${ }^{2}$
}

\author{
Author for correspondence: T. Martin Embley. Tel. +4471938 8760. Fax +4471938 8754. \\ e-mail: TME@NHM.IC.AC.UK
}

\author{
'Microbiology Group, Department of Zoology, The Natural History Museum, Cromwell Road, \\ London SW7 5BD, UK \\ ${ }^{2}$ Institute of Freshwater Ecology, Windermere Laboratory, The Ferry House, Ambleside, Cumbria \\ LA22 OLP, UK
}

Keywords: phylogeny, endosymbionts, anaerobic ciliates, methanogens, hydrogenosomes, small subunit rRNA sequences

\section{Anaerobic habitats and distribution of the anaerobic phenotype among eukaryotes}

Anaerobic environments are widespread and common: they include marine and freshwater sediments, waterlogged soils, sewage and the gastro-intestinal tracts of animals. The interior of organic aggregates with diameters greater than about $1 \mathrm{~mm}$ may also be anaerobic if diffusion is the only means by which $\mathrm{O}_{2}$ can penetrate (Fenchel \& Finlay, 1991a). Anaerobic environments often contain large numbers of prokaryotes and these in turn support a variety of anaerobic protozoa which feed on them (Fenchel \& Finlay, 1990). Protozoa which live exclusively in anaerobic environments and which lack the enzymes necessary for oxidative phosphorylation can be divided into two groups. The first includes protozoa which are probably 'primitively' anaerobic, principally the trichomonads, diplomonads and microsporidia; these taxa form the core of the phylum Archezoa (Cavalier-Smith, 1987). On the basis of their small subunit (SSU) ribosomal (r)RNA sequences, the few Archezoa sequenced so far form the basal lineages in the eukaryotic tree (Vossbrinck et al., 1987; Sogin et al., 1989; Chakrabarti et al., 1992; Van Keulen et al., 1993; Leipe et al., 1993). All Archezoa lack mitochondria and Variomorpba necatrix has prokaryote-sized (70S) ribosomes (Vossbrinck et al., 1987). The Archezoa are living 'relics' of the earliest phase of anaerobic eukaryotic evolution (Cavalier-Smith, 1987) which occurred when free oxygen was scarce in the atmosphere.

The production of an oxygen-rich atmosphere by oxygenic photosynthetic prokaryotes around 2 billion years ago (Schopf, 1992) is one of the pivotal events in the history of the Earth. It allowed the development of highenergy-yielding pathways in bacteria based on the use of $\mathrm{O}_{2}$ as terminal electron acceptor. In aerobic eukaryotes the final stages of oxidative phosphorylation are carried out in mitochondria which are themselves the descendants of endosymbiotic alpha-proteobacteria which possessed this ability (Yang et al., 1985; Cedergren et al., 1988; Gray et al., 1989). The earliest branching eukaryotes which clearly contain mitochondria and from which rRNA sequences have been analysed are members of the lineage containing Euglena and Trypanosoma (Euglenozoa; Sogin, 1991; Gray, 1992). If one invokes a monophyletic origin for all mitochondria [but see Gray (1992) for a detailed discussion of evidence for and against this hypothesis] then anaerobic eukaryotes which branch off from the eukaryotic tree later than the Euglenozoa, and which lack mitochondria, are probably secondarily adapted for the colonization of anaerobic habitats: these are the second group of anaerobic protozoa. Anaerobic habitats contain a diversity of anaerobic flagellates and amoebae (Fenchel \& Finlay, 1990; Milnikov, 1991) many of which are probably primitively anaerobic. Eukaryotes which lack mitochondria and have clearly diverged (see Sogin, 1991) after the Euglenozoa include rumen chytrid fungi and ciliates, and a small number of free-living ciliates (Fenchel et al., 1977; Müller, 1988; Fenchel \& Finlay, 1991a). The biology and ecology of free-living anaerobic ciliates have recently been reviewed (Fenchel \& Finlay, 1991a). It is the evolutionary relationships of freeliving anaerobic ciliates and their endosymbiotic methanogens with which we are concerned in the present review.

\section{Anaerobic free-living ciliates}

The existence of free-living strictly anaerobic ciliates was established by Fenchel et al. (1977). They were able to show that ciliates isolated from sulphide-rich sands, including members of the genera Caenomorpha, Metopus, 

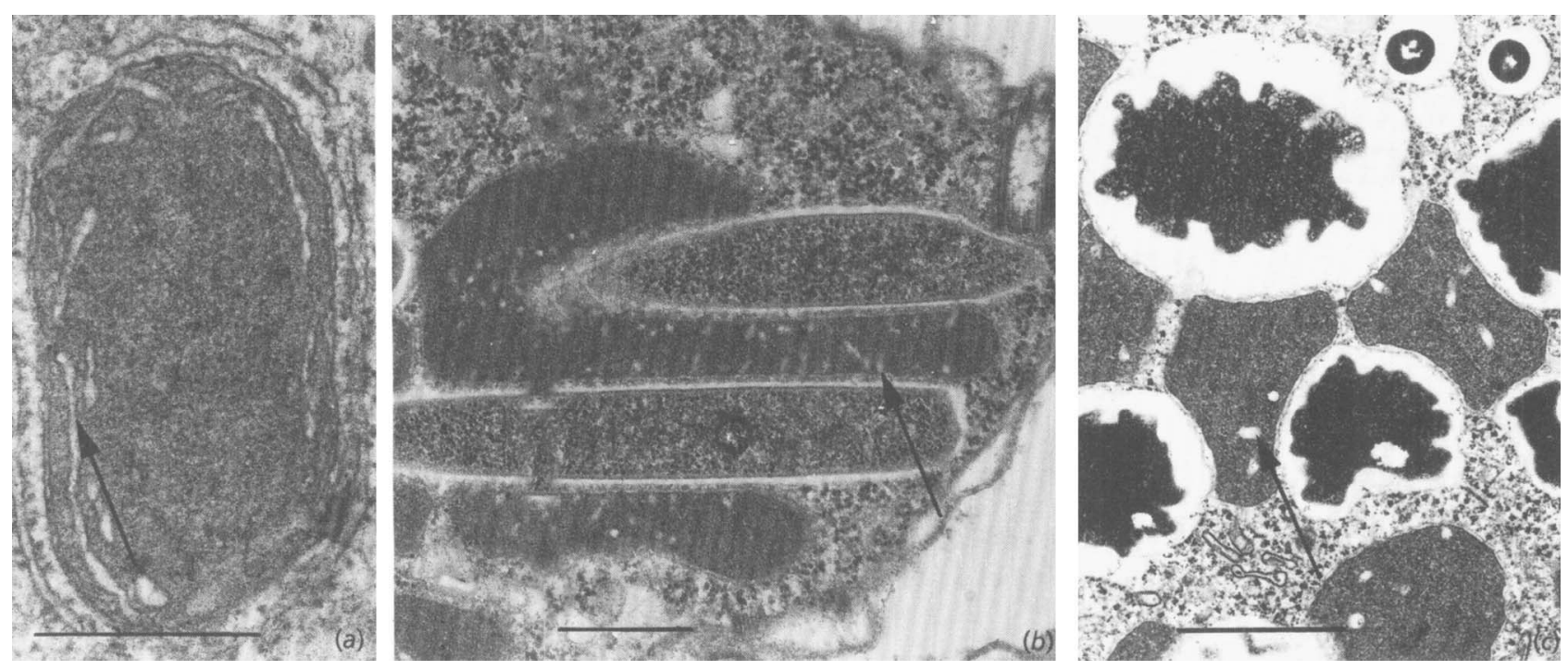

Fig. 1. Electron micrographs of thin sections through hydrogenosomes from free-living anaerobic ciliates belonging to three independent lineages. In each case, the structures have double membranes and the inner membrane shows mitochondrion-like infolding (arrows). (a) From Metopus contortus (scale bar, $0.5 \mu \mathrm{m}$ ); modified from Finlay \& Fenchel (1989). (b) From Cyclidium porcatum (scale bar, $0.5 \mu \mathrm{m}$ ); modified from Esteban et al. (1993). (c) From Trimyema sp. (scale bar, $1 \mu \mathrm{m})$.

Parablepharisma, Plagiopyla, Saprodinium and Sonderia, lacked mitochondria and cytochrome oxidase. Subsequent work on these and other free-living ciliates (Finlay \& Fenchel, 1989; Broers et al., 1991; Esteban et al., 1993) demonstrated that although they lacked mitochondria, they did contain specialized redox organelles called hydrogenosomes (Fig. 1a-c). Hydrogenosomes are not confined to ciliates; they were first described in trichomonads (Lindmark \& Müller, 1973; Müller, 1988) and have been detected in species of the rumen chytrid Neocallimastix (Yarlett et al., 1986; Marvin-Sikkema et al., 1992). The biochemistry of hydrogenosomes in ciliates has been studied mainly in the rumen ciliates Dasytricha, Isotricha and Polyplastron (Yarlett et al., 1981, 1983, 1984) but the biochemistry is probably the same or similar in those free-living ciliates which produce $\mathrm{H}_{2}$ (Fenchel \& Finlay, 1992). The hydrogenosomes in Dasytricha ruminantium oxidize pyruvate with the production of ATP, $\mathrm{CO}_{2}$,
$\mathrm{H}_{2}$ and acetate (Yarlett $e$ t al., 1981, 1982). They contain a pyruvate:ferredoxin oxidoreductase which reduces a ferredoxin and an hydrogenase which catalyses the reoxidation of the ferredoxin with the production of $\mathrm{H}_{2}$. It is this $\mathrm{H}_{2}$-evolving fermentation which is thought to underpin the symbiosis between anaerobic ciliates and endosymbiotic methanogens.

\section{Symbioses between anaerobic free-living ciliates and methanogenic Archaea}

The earliest evidence that some of the intracellular bacteria observed in anaerobic ciliates (Fenchel et al., 1977) might be methanogens came from observations of their UVinduced autofluorescence (Vogels et al., 1980). It was subsequently shown (Van Bruggen et al., 1983) that the fluorescing compound was coenzyme $\mathrm{F}_{420}$, which is found mainly in methanogenic Archaea (Jones et al., 1987). Cells

Fig. 2. (a) The ciliate Metopus palaeformis (living). (b) Autofluorescing rod-shaped methanogens in Metopus palaeformis. (c) The ciliate Metopus contortus (living). (d) Autofluorescing methanogens in two cells of Metopus contortus. (e) Two living individuals of the ciliate Plagiopyla frontata. ( $f$ ) Autofluorescing methanogens in Plagiopyla frontata. ( $(\mathrm{g}, \mathrm{h}, \mathrm{i})$ Photographic sequence of the same microscopic field. The field contains whole fixed cells (Bacteria, Archaea, eukaryotes) simultaneously probed with fluorescently labelled oligonucleotides specific for all eukaryotes, and for the ciliate Metopus palaeformis. (g) Phase-contrast image showing M. palaeformis and various other eukaryotes. (h) Epifluorescence image following excitation of the fluorescein-labelled eukaryote-specific probe. (i) Epifluorescence image following excitation of the specific rhodamine-labelled $M$. palaeformis probe. Two $M$. palaeformis cells and a cyst of the ciliate are obvious. (j) Confocal image of an individual Metopus contortus cell probed with a rhodamine-labelled oligonucleotide specific to its polymorphic endosymbiotic methanogen. (k) Autofluorescing endosymbiotic methanogens in the ciliate Trimyema sp. (I) The ciliate Trimyema sp. showing its endosymbiotic methanogens, of various shapes and sizes fluorescing in response to the specific symbiont probe. $(\mathrm{m})$ Confocal image of the dual-probed (Bacteria and Archaea) ciliate Cyclidium porcatum (centre). The Bacteria and Archaea fluoresce green and red respectively, within the intracellular tripartite complex of the ciliate. The red-fluorescing clusters surrounding the ciliate are cells of the methanogen Methanosarcina sp. Final magnifications are as follows: (a) $\times 290$; (b) $\times 390$; (c) $\times 290$; (d) $\times 720$; (e) $\times 290$; (f) $\times 390$; (g) $\times 140$; (h) $\times 140$; (i) $\times 140 ;(j) \times 240 ;(k) \times 800 ;(l) \times 800 ;(m) \times 570$. 

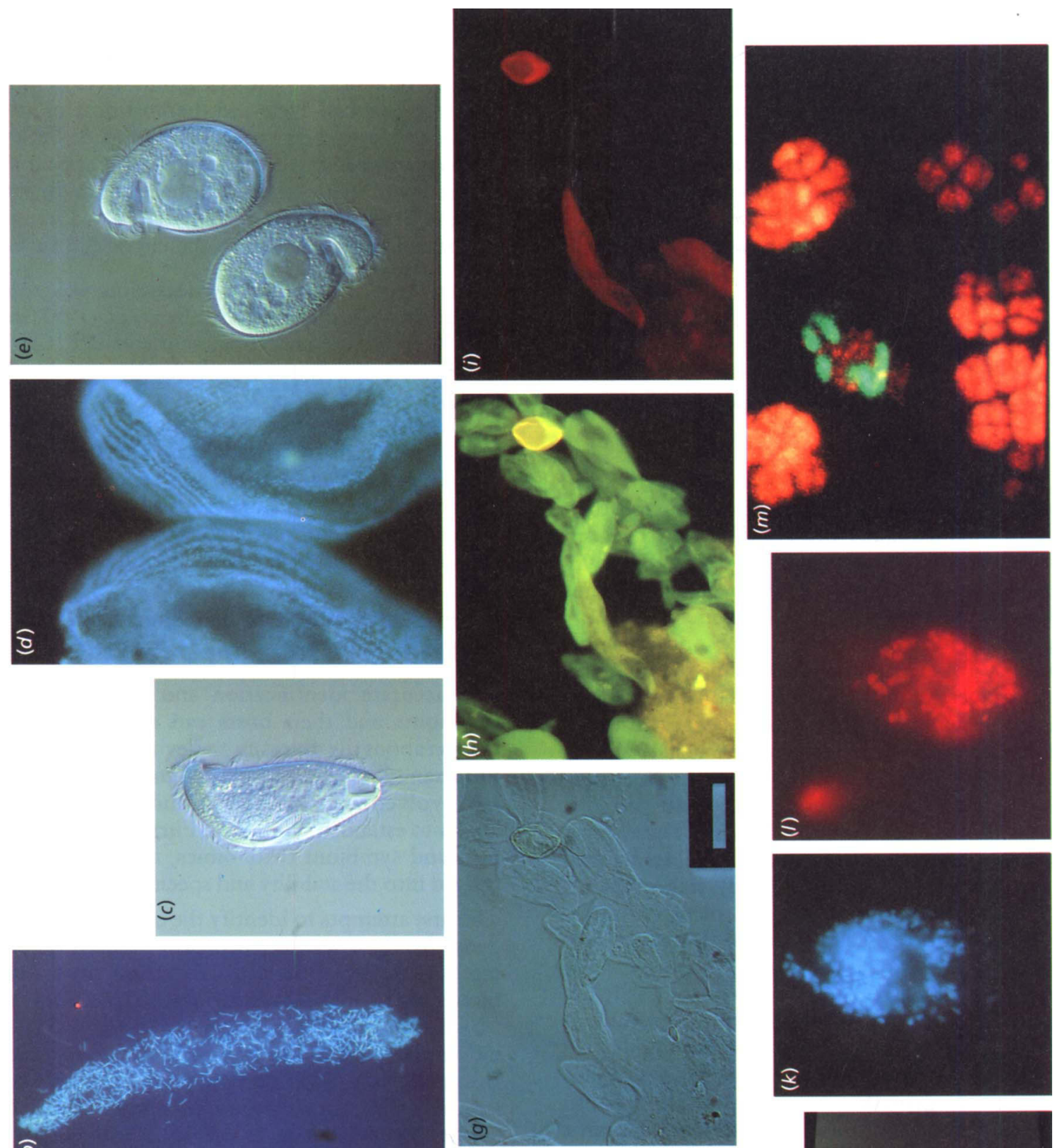

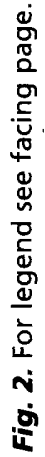
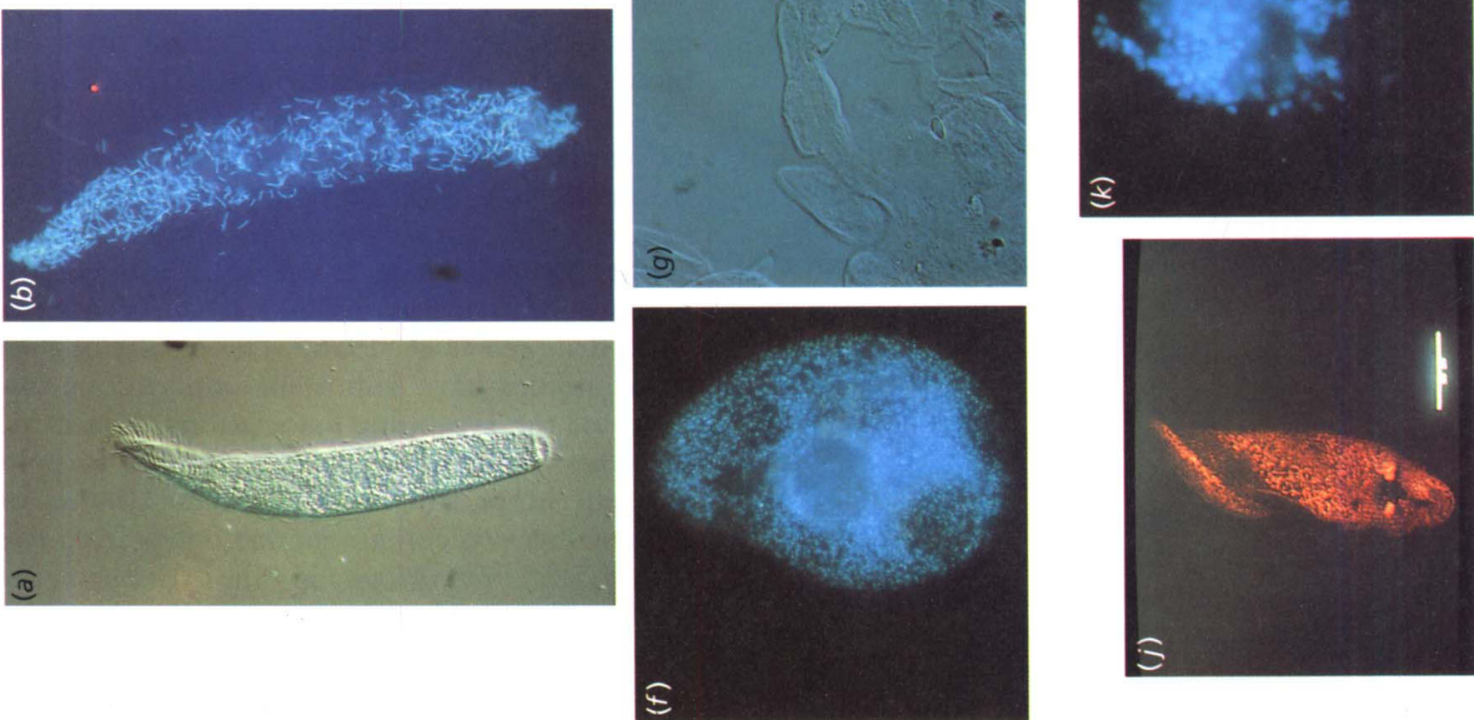

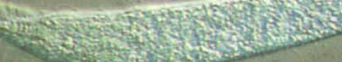

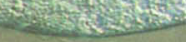

(⿻) 
of Metopus palaeformis, Metopus contortus and Plagiopyla frontata which contain fluorescing bacteria (Fig. 2a-f) also produce methane (Fenchel \& Finlay, 1992). Anaerobic protozoa are the only eukaryotes which are known to contain endosymbiotic Archaea, although symbioses between eukaryotes and Bacteria are common and well documented (Margulis, 1993). The intracellular methanogens probably gain energy by reducing $\mathrm{CO}_{2}$ with the waste $\mathrm{H}_{2}$ from host hydrogenosomes (Van Bruggen $e$ t al., 1983; Jones et al., 1987). The benefits to the host are less obvious and in most ciliates they are unknown. However, some large ciliates including Metopus contortus and Plagiopyla frontata do benefit, since their growth rate and yield are reduced if the methanogens are specifically inhibited (Fenchel \& Finlay, 1991b). The physiology and ecology of ciliate-methanogen consortia have recently been reviewed by Finlay \& Fenchel (1992b).

\section{Ultrastructural aspects of host/endosymbiont interactions}

Electron microscopy has revealed that the symbioses between different free-living anaerobic ciliates and their endosymbiotic methanogens present different levels of structural integration. In Metopus palaeformis the symbionts are rod-shaped (Fig. 3a) and apparently unattached to host hydrogenosomes (Finlay \& Fenchel, 1991a). However, growth and division of the symbiont are closely coupled to host growth and division (Finlay \& Fenchel, 1992a). This suggests a tight dependence of the symbiont on host metabolism but a concomitant benefit for the host has not been demonstrated (Finlay \& Fenchel, 1991a). A strain of Metopus contortus isolated from marine sand contained a variety of shapes and sizes of endosymbiotic methanogens (Finlay \& Fenchel, 1991b). These were interpreted as representing the morphological transformation of a single symbiont (Fig. $3 \mathrm{~b}-\mathrm{d}$ ) rather than a mixture of different endosymbionts. A plausible transformation series could be assembled from electron micrographs ranging from small rods/plates to large thinwalled discs closely attached to hydrogenosomes. It has been suggested that the close juxtaposition of symbiont and hydrogenosome facilitates $\mathrm{H}_{2}$ transfer (Finlay \& Fenchel, 1991b). Metopus contortus benefits from its endosymbionts since its growth rate and yield are reduced when they are treated with the methanogen inhibitor bromoethanesulphonic acid (Fenchel \& Finlay, 1991b).

The only other ciliate for which a morphological transformation of the endosymbiont has been suggested is an isolate of the freshwater ciliate Trimyema (Finlay et al., 1993). Thin sections of this ciliate revealed electron-dense bodies (Fig. 4), of various shapes and sizes, which could be arranged into a series of stages in a morphological transformation. Some of the electron-dense bodies are considerably larger in section than others and they show indentation of their outline. Each of these large morphotypes is enclosed by a cell wall and each is surrounded by hydrogenosomes.

Transmission electron micrographs reveal that the symbionts in Plagiopyla frontata are closely integrated into the host life-cycle (Fenchel \& Finlay, 1991c). The symbiotic methanogens and host hydrogenosomes form aggregates arranged like stacks of coins in which the two partners alternate for position (Fig. 5a). Similar structures have been observed in Plagiopyla minuta and Lechriopyla mystax (Berger \& Lynn, 1992). In Plagiopyla frontata the timing of the reproduction of the symbionts is closely integrated with the host cell-cycle and the host obtains an energetic advantage from the symbiosis (Fenchel \& Finlay, 1991b). In Plagiopyla nasuta, the endosymbionts appear to be quite different and they do not form stacks with the hydrogenosomes. They are long rods (Fig. 5b) which are always orientated perpendicular to the ciliate cell surface.

A new type of symbiotic interaction was recently discovered and described by Esteban et al. (1993) in the small (20-30 $\mu \mathrm{m}$ long) anaerobic scuticociliate Cyclidium porcatum. Each ciliate contains a tightly organized complex (ca. $8 \mu \mathrm{m}$ ) of three independent components: about 15 hydrogenosomes, and two different sized prokaryotes (Fig. 5c). There are approximately five large, thick rods and about 40 small, slim rods associated with the complex in each ciliate. The small rods show the characteristic autofluorescence of methanogenic Archaea but the larger rods resemble Bacteria and do not autofluoresce.

\section{Identification of the endosymbiotic methanogens from anaerobic ciliates}

The accurate identification and classification of endosymbionts and their hosts can reveal important information about the diversity and evolution of the symbioses. For example, it can reveal how many different organisms are involved in an association and how widespread is the ability to establish symbioses. Furthermore, by comparing host and symbiont taxonomies, it is possible to gain an insight into the stability and specificity of the associations.

The first attempts to identify the endosymbiotic methanogens from anaerobic protozoa relied on traditional methods of isolation and cultivation. Rod-shaped symbionts were isolated from washed cells of the ciliate Metopus striatus (Van Bruggen et al., 1984) and from individuals of the giant amoeba Pelomyxa palustris (Van Bruggen et al., 1988). Both methanogens were classified as strains of Methanobacterium formicicum. A polymorphic methanogen classified as Methanoplanus endosymbiosus was subsequently isolated from a strain of Metopus contortus (Van Bruggen et al., 1986). The results of these culturebased studies have important implications for the specificity of the symbiotic associations. Strains of Metbanobacterium formicicum appear to be able to colonize very different hosts and the congeners Metopus striatus and Metopus contortus contain methanogens from two different orders; $M$. formicicum in the Methanobacteriales and Methanoplanus endosymbiosus from the Methanomicrobiales. However, two things should be noted about these studies; it was not demonstrated that the cultures actually were the endosymbionts (e.g. by reinfection or in situ probing) rather than food bacteria or contaminants, and secondly, only a small number of characters were used to identify and classify the isolates. 

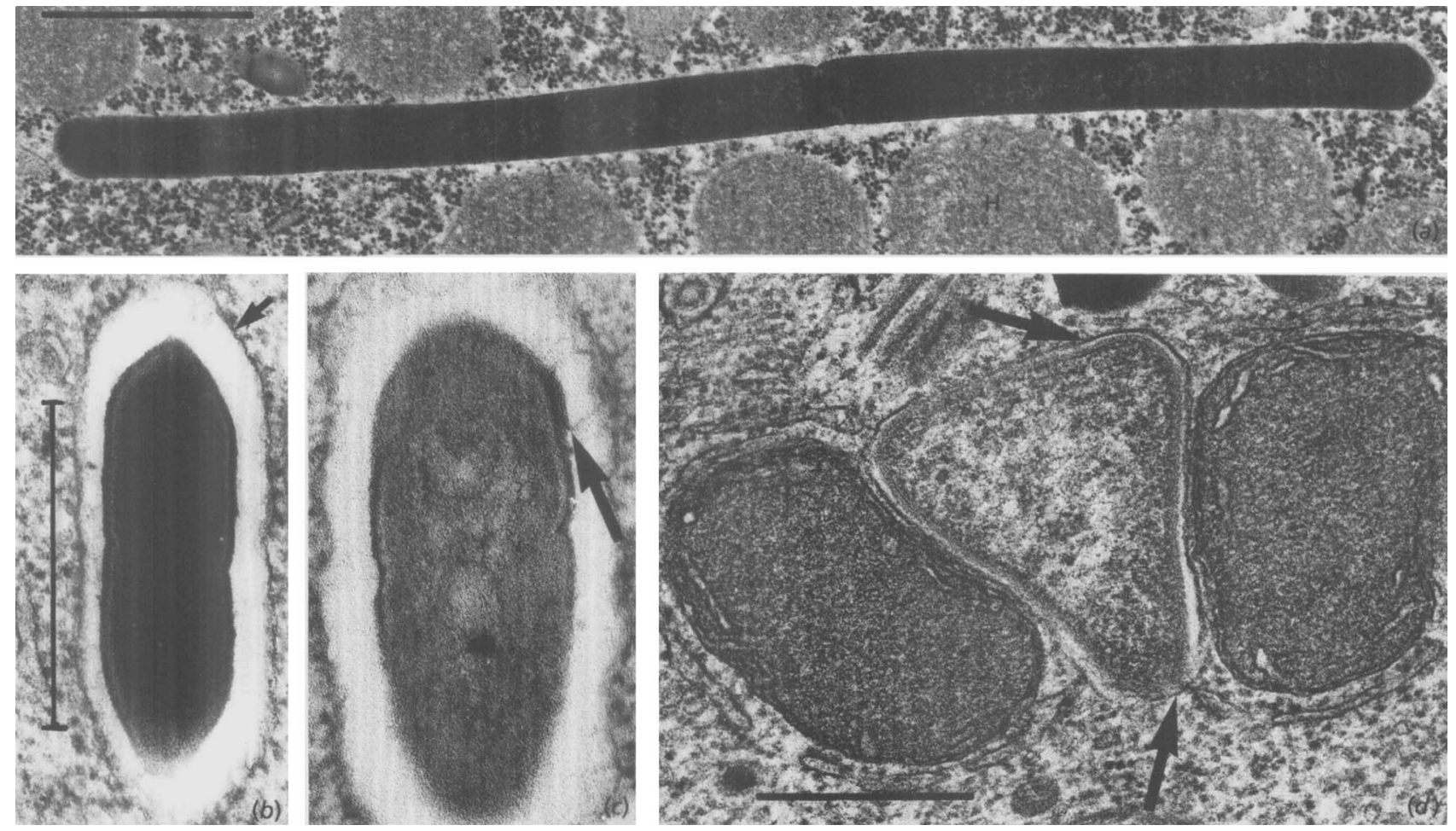

Fig. 3. (a) The permanently rod-shaped methanogen in Metopus palaeformis. The specimen shown has reached maximum length $(6.6 \mu \mathrm{m})$ before division. The methanogen is closely associated with, but apparently not attached to, the hydrogenosomes $(H)$ of the ciliate. $(b, c, d)$ Sequential stages in the polymorphic transformation of the symbiotic methanogens in Metopus contortus. The vacuolar membrane (arrow in b) is always obvious. The cell wall of the methanogen is stripped off (arrow in c) and the 'plasticized' wall-less methanogen, still enclosed in a ciliate vacuolar membrane (arrows in d) is attached to hydrogenosomes. All adapted from Finlay \& Fenchel (1991b). Scale bars: $1 \mu \mathrm{m}$ in (a); $0.5 \mu \mathrm{m}$ in (b)-(d).

Over the past few years molecular tools have been developed which allow the identities of uncultured bacteria such as endosymbionts to be precisely determined. Fundamental to this approach is the comparative analysis of rRNA sequences to classify and identify microorganisms (Woese, 1987; Sogin, 1991) and the ease by which rRNA sequences can be recovered from uncultured microbes using the polymerase chain reaction (PCR) and specific primers (Saiki et al., 1988).

\section{Use of 165 rRNA sequences to classify and identify the methanogen endosymbionts of anaerobic ciliates}

The advantages of $\mathrm{rRNAs}$ for studying microbial phylogeny have been extensively discussed (Woese, 1987). Of particular relevance to the present discussion is that, on the basis of rRNA sequence comparisons, all cellular life can be divided into three domains; the Bacteria, Archaea and Eucarya (Woese et al., 1990; Winker \& Woese, 1991).
Each domain contains some conserved sequence motifs which are absent from the other two. It is thus relatively simple to design PCR primers that will specifically amplify rRNA sequences from one phylogenetic group in the presence of competing templates from another (Giovannoni et al., 1990; Amann et al., 1991; Fry et al., 1991). On present data the methanogen phenotype appears to be restricted (with one exception Methanopyrus kandleri; Burggraf et al., 1991) to a phylogenetically coherent subdomain of the Archaea called the Euryarchaeota (Woese et al., 1990). PCR primers which amplify rRNA genes from the Euryarchaeota without concomitant amplification of ciliate rRNA genes have been designed (Embley et al., 1992a) using published methanogen sequences (Larsen et al., 1993). Using these primers it is not necessary to purify symbiont DNA prior to amplification and PCR can be done directly on crude DNA preparations or small numbers of heat-lysed ciliates (Embley et al., 1992a, b, 1994; Finlay et al., 1993). Using PCR primers specific for eukaryote SSU rRNA genes (Embley et al., 1992a) it is also possible to recover host sequences from the same crude DNA preparations. 


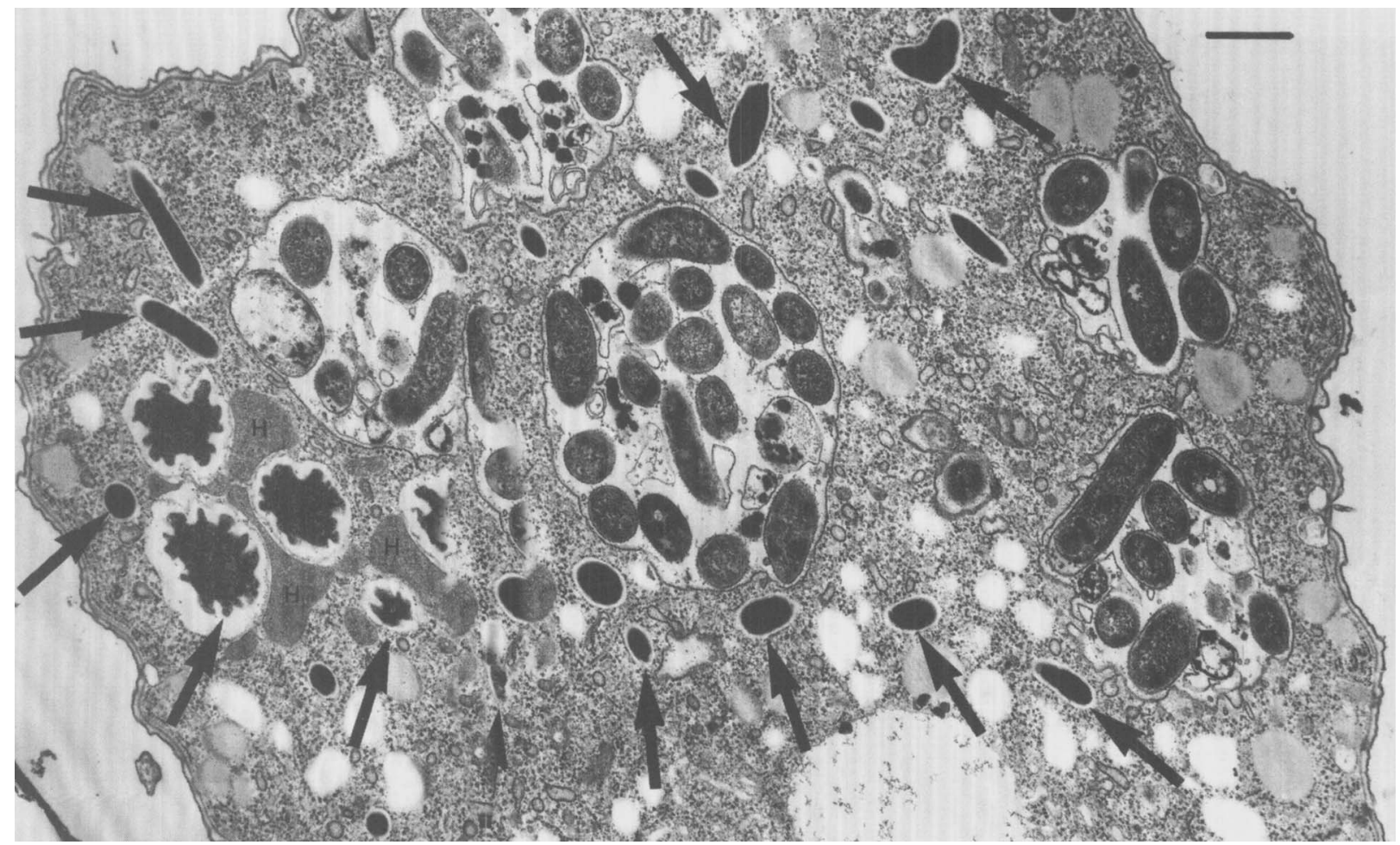

Fig. 4. Polymorphs of the endosymbiotic methanogen (arrows) in Trimyema sp. The final stages of morphological transformation are always attached to hydrogenosomes $(\mathrm{H})$ of the ciliate. The large digestive vacuoles in the section contain ingested food bacteria which always appear less electron-dense than the symbiotic methanogens. Scale bar, $1 \mu \mathrm{m}$. Adapted from Finlay et al. (1993).

Once a sequence has been obtained, the simplest way to demonstrate that it belongs to an endosymbiont or to a specific host is to carry out an in situ hybridization experiment (e.g. Fig. 2g-i). Oligonucleotide probes to rRNA (which can be designed from the sequence of a symbiont or host PCR product) can be labelled with fluorescent dyes (DeLong et al., 1989) and used to probe intact protozoa which have been made permeable by treatment with paraformaldehyde (Amann et al., 1991; Embley et al., 1992a). rRNA sequences are mosaics of conserved, semi-conserved and very variable sequences (Woese et al., 1983; Woese, 1987) and it is relatively simple to design highly specific probes by targeting an appropriate region (Stahl \& Amann, 1991). Probes to rRNA are very sensitive, as ribosomes are abundant in actively growing cells (DeLong et al., 1989).

The first symbiosis to be examined in detail using molecular methods (Embley et al., 1992a) was that between Metopus palaeformis and its rod-shaped endosymbiont (Finlay \& Fenchel, 1991a). A single endosymbiont sequence was obtained using PCR which, when analysed, demonstrated that the symbiont was a member of the genus Methanobacterium (Fig. 6). Two fluorescent oligonucleotide probes were designed to bind to the symbiont rRNA sequence and used to probe intact Metopus palaeformis and demonstrate that the sequence originated from intracellular bacteria. The symbiont sequence was different to published sequences from freeliving methanogens including Metbanobacterium formicicum (Lechner et al., 1985). The 16S rRNA gene from the strain of Methanobacterium formicicum previously isolated from Metopus striatus (Van Bruggen et al., 1984) has also been sequenced (Embley et al., 1994). Phylogenetic analysis revealed that it too is different from Methanobacterium formicicum, but it is also different to the Metopus palaeformis endosymbiont and it is probably a new species (Fig. 6).

Molecular analyses (Embley et al., 1992b) have confirmed that the polymorphic methanogens in an isolate of Metopus contortus represent stages in the morphological transformation of a single endosymbiont (Finlay \& Fenchel, 1991b), rather than a mixture of different methanogens. Experiments designed to selectively amplify symbiont sequences recovered only a single methanogen sequence from heat-lysed ciliates. When a specific fluorescent probe was designed to this sequence and used to probe Metopus contortus it hybridized to a range of sizes and shapes of fluorescing intracellular bacteria (Fig. 2i). The same intracellular bacteria also gave positive signals with a control Archaea-specific probe (Stahl \& Amann, 1991). Phylogenetic analysis of the symbiont sequence (Embley et al., 1994) demonstrated that it is closely related (but different) to the $16 \mathrm{~S}$ rRNA sequence from the free-living methanogen Methanocorpusculum parvum. 

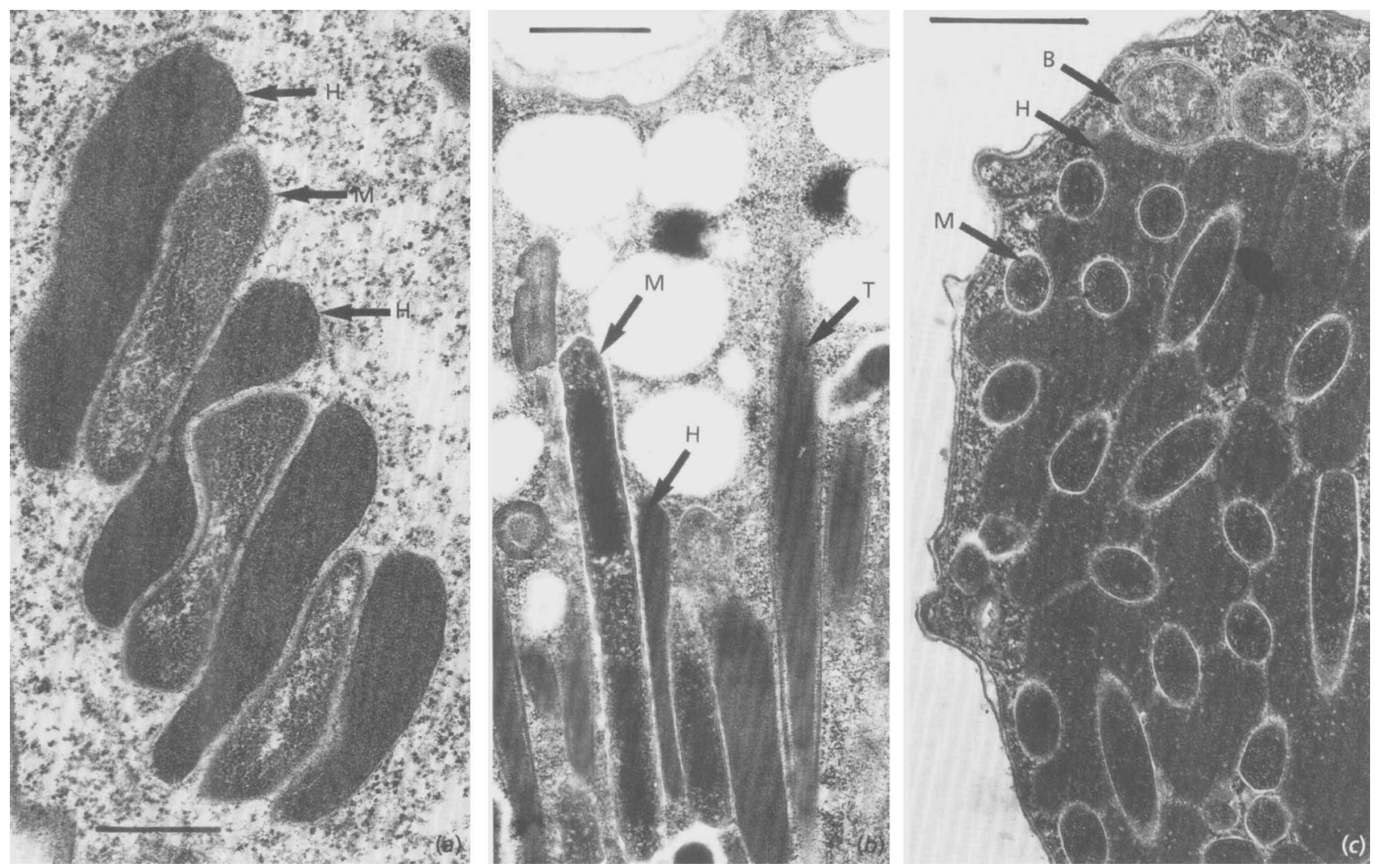

Fig. 5. (a) A characteristic stack of alternating hydrogenosomes $(\mathrm{H})$ and methanogens $(\mathrm{M})$ in Plagiopyla frontata. The components of each stack divide synchronously immediately prior to division of the ciliate. (b) Methanogens (M), hydrogenosomes $(\mathrm{H})$ and trichocysts $(\mathrm{T})$ in Plagiopyla nasuta. All three structures are typically oriented perpendicular to the outer membrane of the ciliate. (c) The tripartite complex of methanogens $(\mathrm{M})$, hydrogenosomes $(\mathrm{H})$ and unidentified Bacteria (B) in Cyclidium porcatum. The micrograph shows a transverse section through the anterior half of the ciliate. All scale bars represent $1 \mu \mathrm{m}$. (c) Adapted from Esteban et al. (1993).

As previously mentioned, Trimyema sp. (Finlay et al., 1993 ) is the other ciliate in which a single endosymbiont appears to undergo morphological transformation. rRNA sequences recovered from this consortium confirm, once again, that a single symbiont is morphologically transformed (Fig. 2k, 1). When the symbiont sequence was analysed (Embley et al., 1994) its nearest relatives were the Metopus contortus endosymbiont and Methanocorpusculum parvum (Fig. 6). It is fascinating (and may be significant to understanding the phenomenon) that in the two cases where a morphological transformation has been documented (in taxonomically unrelated marine and freshwater ciliates) the symbionts are very closely related to each other.

Molecular analysis of the endosymbionts in Plagiopyla frontata and Plagiopyla nasuta (Embley et al., 1994) confirmed ultrastructural evidence (Fig. 5a, b) that they are different methanogens. The symbiont in Plagiopyla frontata is closely related to the free-living Methanolobus tindarius which was originally isolated from marine sediment (König \& Stetter, 1982). The sequence recovered from lysed cells of Plagiopyla nasuta forms a deep branching lineage within the radiation of the Methanomicrobiales group (Fig. 6). This level of sequence divergence is similar to that between some of the genera of free-living methanogens in Fig. 6. The exact position of the Plagiopyla nasuta endosymbiont could not be resolved, as it shifted according to the method of analysis and the composition of reference sequences. Cells of Plagiopyla frontata and Plagiopyla nasuta exhibit high levels of background autofuorescence when fixed with paraformaldehyde and it has not yet been possible to confirm the origin of symbiont sequences from these two hosts by in situ probing. However, identical sequences were recovered from three independent preparations of micromanipulated ciliates for which fluorescence microscopy was used to check for the absence of free-living methanogens. Furthermore, electron micrographs of the Plagiopyla frontata endosymbiont (Fig. 5a, and B. J. Finlay, unpublished) show a close resemblance to published micrographs of Methanolobus tindarius, which has a very thin cell wall (Stetter, 1989).

The precise identities of the prokaryote endosymbionts detected in Cyclidium porcatum have not yet been determined but their higher-level affiliations have been investigated using domain-specific fluorescent probes 


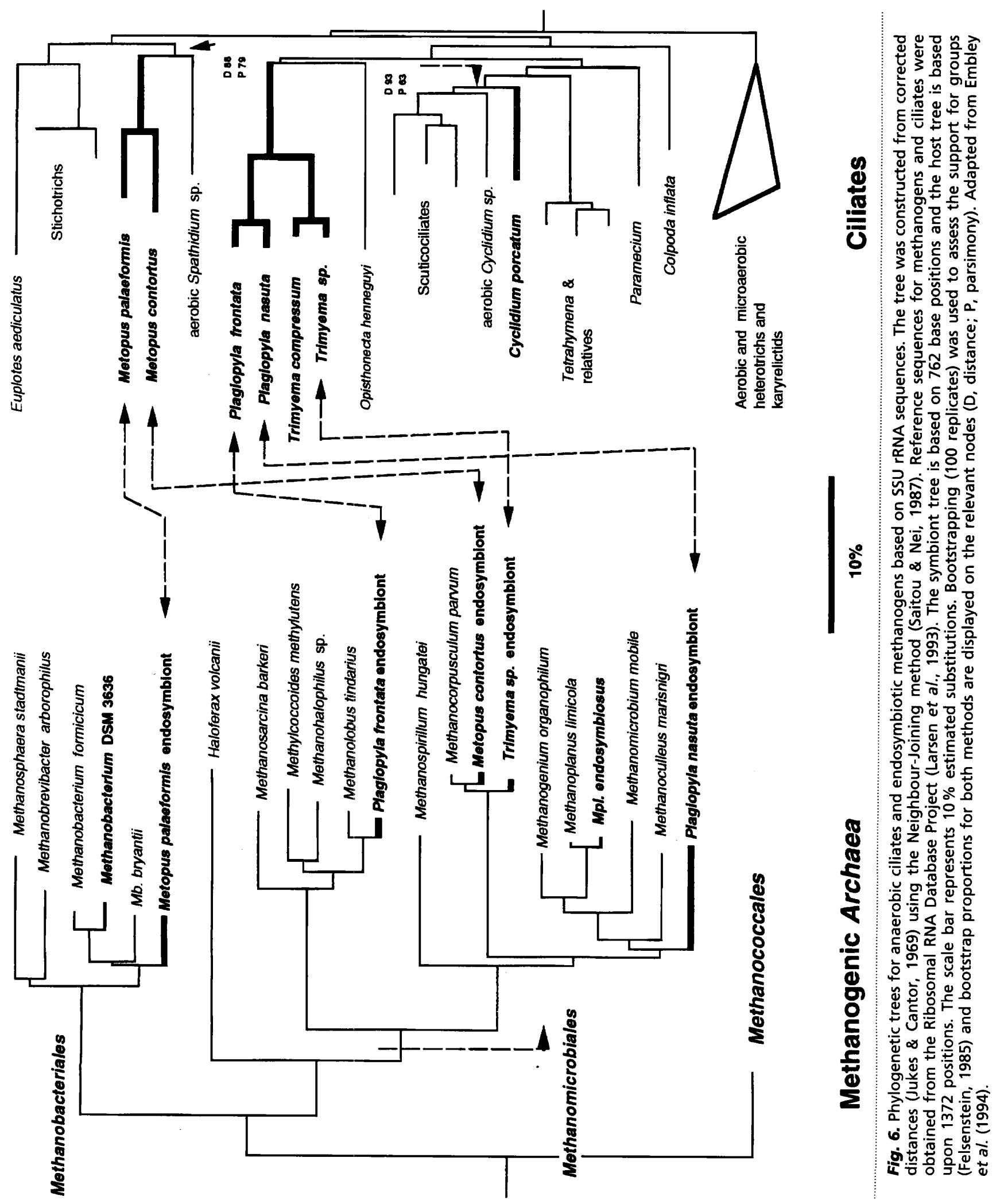


(Esteban et al., 1993). Fig. 2(m) demonstrates the simultaneous application of the Archaea-specific (red) and Bacteria-specific (green) fluorescent oligonucleotide probes (Stahl \& Amann, 1991). The five large prokaryotes clearly fluoresce green and are thus Bacteria whereas the others fluoresce red and are therefore Archaea. In considering the current fascination with biodiversity it is sobering to encounter a eukaryote which is less than $25 \mu \mathrm{m}$ long but which, with its endosymbionts, encompasses the three domains of life!

\section{Phylogenetic diversity of endosymbiotic methanogens and anaerobic ciliates}

Fig. 6 summarizes the phylogenetic relationships of the sequences obtained so far from the endosymbiotic methanogens of anaerobic ciliates. Each sequence is novel, paralleling recent molecular studies which have demonstrated that most environmental micro-organisms represent previously unrecorded lineages (Giovanonni et al., 1990; DeLong, 1992; Furhman et al., 1992). The endosymbiont sequences are distributed throughout the methanogen tree and some endosymbionts are closely related to free-living methanogens. It is clear from these data that symbioses have formed repeatedly and independently. There are currently three major methanogen lineages which have been recognized by analysing $16 \mathrm{~S}$ rRNA sequences of cultured and phenotypically defined taxa; the Methanobacteriales, Methanococcales and the Methanomicrobiales (Woese, 1987; Rouvière et al., 1992). Endosymbionts are drawn from the genus Methanobacterium and they occur throughout the Methanomicrobiales. The distribution of endosymbiont sequences suggests that the ability to form associations with anaerobic ciliates probably predates the divergence of these two major clades. However, the absence of an endosymbiont sequence within the Methanococcales may simply reflect the small sample of sequences available and the trait may eventually prove to be much older.

Fig. 6 also compares the phylogenetic relationships of a sample of anaerobic ciliates based upon SSU rRNA sequences, with the taxonomic distribution of their endosymbionts (Embley et al., 1994). This comparison provides further evidence that the associations have formed repeatedly. There is no congruence between host and endosymbiont trees and thus no evidence of parallel speciation. Congeneric hosts in the genus Metopus and Plagiopyla contain endosymbionts which are more closely related to free-living methanogens than they are to each other. Conversely, polymorphic endosymbionts which are closely related to the free-living species Methanocorspusculum parvum occur in unrelated hosts; Metopus contortus and Trimyema. The pattern of relationships demonstrated between host and endosymbiont (Fig. 6) might be explained if each taxon is a generalist, capable of forming associations with taxonomically different partners. If this is true then the relationships in Fig. 6 simply reflect the associations formed in specific habitats at specific times. This could also explain why the sequence determined for the previously isolated (Van Bruggen $e t$ al., 1986) and cultured methanogen (Methanoplanus endosymbiosus) from Metopus contortus is quite different to the methanogen sequence in the $M$. contortus collected from another locality several years later. The latter is related to Methanocorpusculum parvum, and its identity was confirmed by in situ probing (Embley et al., 1992b). Further experiments to investigate symbionts in the same host from different locations should help to clarify precisely how specific the symbiotic relationships are.

On the basis of SSU rRNA sequences there is evidence for three separate lineages of ciliates possessing the anaerobic phenotype and hydrogenosomes (Embley et al., 1994). These are surrounded by ciliates which possess mitochondria and which are aerobic or microaerobic. However, close scrutiny of the ciliate tree (Fig. 6) reveals that some of the distances between internal nodes are short and that there is only low bootstrap support for some relationships. Three lines of evidence support the independent acquisition of anaerobiosis by the three lineages. There is strong support (Fig. 6) for a sister group relationship between the anaerobic metopids and the aerobic Spathidium sp. (P. Dyal unpublished sequence) and there is moderate support for a sister group relationship between Cyclidium porcatum (a scuticociliate) and the aerobic scuticociliates. Forcing the three anaerobic lineages to form a single lineage increases by 50 steps the length of the optimal tree that can be constructed from the ciliate SSU rRNA sequences using parsimony (Embley et al., 1994). Finally, there is no evidence from cell morphology that Plagiopyla and Trimyema, the metopid heterotrichs, and the scuticociliates, form a monophyletic group (Corliss, 1979).

If one accepts that the topology in Fig. 6 is an accurate reflection of anaerobic ciliate evolution, then the ability to live anaerobically has arisen at least three times within the ciliate radiation. As representatives in each of these three lineages have hydrogenosomes it is reasonable to assume that hydrogenosomes have also evolved on three independent occasions. The hydrogenosomes in Metopus sp., Trimyema sp. and Cyclidium porcatum (Finlay \& Fenchel, 1989; Esteban et al., 1993) have double membranes and the inner membrane is sometimes folded to form cristae-like structures; in electron micrographs they strongly resemble mitochondria (Fig. $1 \mathrm{a}-\mathrm{c}$ ). There are currently two theories to explain the origins of hydrogenosomes; that they represent modified mitochondria (Cavalier-Smith, 1987; Finlay \& Fenchel, 1989), or that they represent a separate endosymbiosis involving a pyruvate-oxidizing Clostridium-like bacterium (Müller, 1988). We accept that the origins of hydrogenosomes may be different in taxa such as trichomonads (Lindmark \& Müller, 1973; Müller, 1988) which are probably primitively anaerobic. However, the ciliate tree based upon SSU rRNA sequences strongly suggests that in the freeliving ciliates at least, hydrogenosomes are derived from existing organelles and on the basis of ultrastructural evidence the most likely candidate is a mitochondrion. A key task for understanding the evolutionary development of anaerobiosis from aerobic eukaryotes is now to identify 
the origins and locations of the genes coding for the anaerobic physiology.

Financial assistance from the Natural Environment Research Council supported the work of B. J.F. The authors would like to thank Ken Clarke, Pat Dyal, Dr Geneveva Esteban, Ruth Hindle and Dr Robert Hirt for invaluable collaboration on projects relating to methanogen and ciliate phylogeny and symbiosis.

\section{References}

Amann, R. I., Springer, N., Ludwig, W., Gortz, H.-D. \& Schleifer, K.-H. (1991). Identification and in situ phylogeny of uncultured bacterial endosymbionts. Nature 351, 161-164.

Berger, J. \& Lynn, D. H. (1992). Hydrogenosome-methanogen assemblages in the echinoid endocommensal plagiopylid ciliates, Lechriopyla mystax Lynch, 1930 and Plagiopyla minuta Powers, 1933. J Protozool 39, 4-8.

Broers, C. A. M., Stumm, C. K. \& Vogels, G. D. (1991). Axenic cultivation of the anaerobic free-living ciliate Trimyema compressum. J Protozool 38, 507-511.

Burggraf, S., Stetter, K. O., Rouvière, P. \& Woese, C. R. (1991). Methanopyrus kandleri: an archaeal methanogen unrelated to all other known methanogens. Syst Appl Microbiol 14, 346-351.

Cavalier-Smith, T. (1987). Eukaryotes with no mitochondria. Nature 326, 332-333.

Cedergren, R., Gray, M. W., Abel, Y. \& Sankoff, D. (1988). The evolutionary relationships among known life forms. J Mol Evol 28, 98-112.

Chakrabarti, D., Dame, J. B., Gutell, R. R. \& Yowell, C. A. (1992). Characterisation of the rDNA unit and sequence analysis of the small subunit rRNA and 5.8S rRNA genes from Tritrichomonas foetus. Mol Biochem Parasitol 52, 75-84.

Corliss, J. O. (1979). The Ciliated Protozoa. Oxford: Pergamon Press.

DeLong, E. F. (1992). Archaea in coastal marine environments. Proc Natl Acad Sci US A 89, 5685-5689.

DeLong, E. F., Wickham, G. S. \& Pace, N. R. (1989). Phylogenetic stains: ribosomal RNA based probes for the detection of single cells. Science 243, 1360-1363.

Embley, T. M., Finlay, B. J., Thomas, R. H. \& Dyal, P. L. (1992a). The use of rRNA sequences and fluorescent probes to investigate the phylogenetic positions of the anaerobic ciliate Metopus palaeformis and its archaeobacterial endosymbiont. J Gen Microbiol 138, 1479-1487.

Embley, T. M., Finlay, B. J. \& Brown, S. (1992b). RNA sequence analysis shows that the symbionts in the ciliate Metopus contortus are polymorphs of a single methanogen species. FEMS Microbiol Lett 97, 57-62.

Embley, T. M., Finlay, B. J. \& Dyal, P. (1994). Phylogenetic diversity of anaerobic ciliates and their endosymbiotic methanogens. Mol Ecol (submitted).

Esteban, G., Guhl, B. E., Clarke, K. J., Embley, T. M. \& Finlay, B. J. (1993). Cyclidium porcatum n. sp.: a free-living anaerobic scuticociliate containing a stable complex of hydrogenosomes, eubacteria and archaeobacteria. Eur J Protistol 29, 262-270.

Felsenstein, J. (1985). Confidence limits on phylogenies: an approach using the bootstrap. Evolution 39, 783-791.

Fenchel, T. \& Finlay, B. J. (1990). Anaerobic free-living protozoa: growth efficiencies and the structure of anaerobic communities. FEMS Microbiol Ecol 74, 269-276.
Fenchel, T. \& Finlay, B. J. (1991a). The biology of free-living anaerobic ciliates. Eur J Protistol 26, 201-215.

Fenchel, T. \& Finlay, B. J. (1991b). Endosymbiotic methanogenic bacteria in anaerobic ciliates: significance for the growth efficiency of the host. J Protozool 38, 18-22.

Fenchel, T. \& Finlay, B. J. (1991c). Synchronous division of an endosymbiotic methanogenic bacterium in the anaerobic ciliate Plagiopyla frontata Kahl. J Protozool 38, 22-28.

Fenchel, T. \& Finlay, B. J. (1992). Production of methane and hydrogen by anaerobic ciliates containing symbiotic methanogens. Arch Microbiol 157, 475-480.

Fenchel, T., Perry, T. \& Thane, A. (1977). Anaerobiosis and symbiosis with bacteria in free-living ciliates. J Protozool 24, 154-163.

Finlay, B. J. \& Fenchel, T. (1989). Hydrogenosomes in some anaerobic bacteria resemble mitochondria. FEMS Microbiol Lett 65, 311-314.

Finlay, B. J. \& Fenchel, T. (1991a). An anaerobic protozoon, with symbiotic methanogens, living in municipal landfill material. FEMS Microbiol Ecol 85, 169-180.

Finlay, B. J. \& Fenchel, T. (1991b). Polymorphic bacterial symbionts in the anaerobic ciliated protozoon Metopus contortus. FEMS Microbiol Lett 79, 187-190.

Finlay, B. J. \& Fenchel, T. (1992a). An anaerobic ciliate as a natural chemostat for the growth of endosymbiotic methanogens. Eur J Protistol 28, 127-137.

Finlay, B. J. \& Fenchel, T. (1992b). Methanogens and other bacteria as symbionts of free-living anaerobic ciliates. Symbiosis 14, 375-390. Finlay, B. J., Embley, T. M. \& Fenchel, T. (1993). A new polymorphic methanogen, closely related to Methanocorpusculum parvum, living in stable symbiosis within the anaerobic ciliate Trimyema sp. $J$ Gen Microbiol 139, 371-378.

Fry, N. K., Rowthbottom, T. J., Saunders, N. A. \& Embley, T. M. (1991). Direct amplification and sequencing of the $16 \mathrm{~S}$ ribosomal DNA of an intracellular Legionella species recovered by amoebal enrichment from the sputum of a patient with pneumonia. FEMS Microbiol Lett 83, 165-168.

Fuhrman, J. A., McCallum, K. \& Davis, A. A. (1992). Novel major archaebacterial group from marine plankton. Nature 356, 148-149.

Giovannoni, S. J., Britschgi, T. B., Moyer, C. L. \& Field, K. G. (1990). Genetic diversity in Sargasso Sea bacterioplankton. Nature 345, 60-63.

Gray, M. W. (1992). The endosymbiont hypothesis revisited. Int Ren Cytol 141, 233-357.

Gray, M. W., Cedergren, R., Abel, A. \& Sankoff, D. (1989). On the evolutionary origin of the plant mitochondrion and its genome. Proc Natl Acad Sci USA 86, 2267-2271.

Jones, W. J., Nagle, D. P. \& Whitman, W. B. (1987). Methanogens and the diversity of archaebacteria. Microbiol Rev 51, 135-177.

Jukes, T. H. \& Cantor, C. R. (1969). Evolution of protein molecules In Mammalian Protein Metabolism, pp. 21-132. Edited by H. N Munro. New York: Academic Press.

König, H. \& Stetter, K. O. (1982). Isolation and characterisation of Metbanolobus tindarius sp. nov., a coccoid methanogen growing only on methanol and methylamines. Zentralbl Bakteriol Mikrobiol Hyg 1 Abt Orig C 3, 478-490.

Larsen, N., Olsen, G. J., Maidak, B. L., McCaughey, M. J., Overbeek, R., Macke, T. J., Marsh, T. L. \& Woese, C. R. (1993). The ribosomal database project. Nucleic Acids Res 21, 3021-3023.

Lechner, K., Wich, G. \& Bock, A. (1985). The nucleotide sequence of the 16s rRNA gene and flanking regions from Methanobacterium 
formicicum: on the phylogenetic relationship between methanogenic and halophilic archaebacteria. Syst Appl Microbiol 6, 157-163.

Leipe, D., Gunderson, J. H., Nerad, T. A. \& Sogin, M. L. (1993). Small subunit RNA of Hexamita inflata and the quest for the first branch in the eukaryotic tree. Mol Biochem Parasitol 59, 41-48.

Lindmark, D. G. \& Müller, M. (1973). Hydrogenosome, a cytoplasmic organelle of the anaerobic flagellate Trichomonas vaginalis, and its role in pyruvate metabolism. J Biol Chem 248, 7724-7728.

Margulis, L. M. (1993). Symbiosis in Cell Evolution, 2nd edn. Oxford: W. H. Freeman \& $\mathrm{Co}$.

Marvin-Sikkema, F. D., Lahpor, G. A., Kraak, M. N., Gottschal, J. C. \& Prins, R. A. (1992). Characterization of an anaerobic fungus from llama faeces. J Gen Microbiol 138, 2235-2241.

Milnikov, A. P. (1991). Diversity of flagellates without mitochondria. In The Biology of Free-Living Heterotropbic Flagellates, pp. 144-158. Edited by D. J. Patterson \& J. Larsen. Oxford: Clarendon Press.

Müller, M. (1988). Energy metabolism in protozoa without mitochondria. Annu Rev Microbiol 42, 465-488.

Rouvière, P., Mandelco, L., Winker, S. \& Woese, C. R. (1992). A detailed phylogeny of the Methanomicrobiales. Syst Appl Microbiol 15, 363-371

Saiki, R. K., Gelfand, D. H., Stoffel, S., Scharf, S. J., Higuchi, R., Horn, G. T., Mullis, K. B. \& Erlich, H. A. (1988). Primer-directed enzymatic amplification of DNA with a thermostable DNA polymerase. Science 239, 487-491.

Saitou, N. \& Nei, M. (1987). The neighbour joining method: a new method for constructing phylogenetic trees. Mol Biol Evol 4, 406-425.

Schopf, J. W. (1992). The oldest fossils and what they mean. In Major Events in the History of Life, pp. 29-64. Edited by J.W. Schopf. Boston: Jones \& Bartlett.

Sogin, M. L., Gunderson, J. H., Elwood, H. J., Alonso, R. A. \& Peattie, D. A. (1989). Phylogenetic meaning of the kingdom concept: an unusual ribosomal RNA from Giardia lamblia. Science 243, 75-77.

Sogin, M. (1991). Early evolution and the origin of eukaryotes. Curr Opin Genet Devel 1, 457-463.

Stahl, D. A. \& Amann, R. I. (1991). Development and application of nucleic acid probes in bacterial systematics. In Nucleic Acid Tecbniques in Bacterial Systematics, pp. 205-248. Edited by E. Stackebrandt \& M. Goodfellow. Chichester: John Wiley.

Stetter, K. O. (1989). Methanolobus. In Bergey's Manual of Systematic Bacteriology, vol. 3, pp. 2205-2207. Edited by J. T. Staley, M. P. Bryant, N. Pfennig \& J. G. Holt. Baltimore: Williams \& Wilkins.

Van Bruggen, J. J. A., Stumm, C. K. \& Vogels, G. D. (1983). Symbiosis of methanogenic bacteria and sapropelic protozoa. Arch Microbiol 136, 89-95.

Van Bruggen, J. J. A., Zwart, K. B., van Assema, R. M., Stumm,
C. K. \& Vogels, G. D. (1984). Methanobacterium formicicum, an endosymbiont of the anaerobic ciliate Metopus striatus McMurrich. Arch Microbiol 139, 1-7.

Van Bruggen, J. J. A., Zwart, K. B., Hermans, J. G. F., van Hove, E. M., Stumm, C. K. \& Vogels, G. D. (1986). Isolation and characterisation of Metbanoplanus endosymbiosus sp. nov. an endosymbiont of the marine sapropelic ciliate Metopus contortus Quennerstedt. Arch Microbiol 144, 367-374.

Van Bruggen, J. J. A., van Rens, G. L. M., Geertman, E. J. M., Zwart, K. B., Stumm, C. K. \& Vogels, G. D. (1988). Isolation of a methanogenic endosymbiont of the sapropelic amoeba Pelomyxa palustris Greef. J Protozool 35, 20-23.

Van Keulen, H., Gutell, R. R. Gates, M. A., Campbell, S. R., Erlandsen, S. L., Jarroll, E. L., Kulda, J. \& Meyer, E. A. (1993). Unique phylogenetic position of diplomonadida based on complete small subunit ribosomal RNA sequence of Giardia ardeae, G. muris, G. duodenalis and Hexamita sp. FASEB J 7, 223-231.

Vogels, G. D., Hoppe, W. F. \& Stumm, C. K. (1980). Association of methanogenic bacteria with rumen ciliates. Appl Environ Microbiol 136, 89-95.

Vossbrinck, C. R., Maddox, J. V., Friedman, S., DebrunnerVossbrinck, B. A. \& Woese, C. R. (1987). Ribosomal RNA sequences suggests microsporidia are extremely ancient eukaryotes. Nature 326, 411-414.

Yang, D., Oyaizu, Y., Oyaizu, H., Olsen, G. J. \& Woese, C. R. (1985). Mitochondrial origins. Proc Natl Acad Sci USA 82, 4443-4447.

Yarlett, N., Hann, A. C., Lloyd, D. \& Williams, A. G. (1981). Hydrogenosomes in the rumen protozoon Dasytricha ruminantium Schuberg. Biochem J 200, 365-372.

Yarlett, N., Lloyd, D. \& Williams, A. G. (1982). Respiration of the rumen ciliate Dasytricha ruminantium. Biochem J 206, 259-266.

Yarlett, N., Hann, A. C., Lloyd, D. \& Williams, A. G. (1983). Hydrogenosomes in a mixed isolate of Isotricha prostoma and Isotricha intestinalis. Comp Biochem Physiol 74B, 357-364.

Yarlett, N., Coleman, G. S., Williams, A. G. \& Lloyd, D. (1984). Hydrogenosomes in known species of entodiniomorphid protozoa. FEMS Microbiol Lett 21, 15-19.

Yarlett, N., Orpin, C. G., Munn, E. A. \& Greenwood, C. A. (1986). Hydrogenosomes in the rumen fungus Neocallimastix patriciarum. Biochem J 236, 729-739.

Winker, S. \& Woese, C. R. (1991). A definition of the domains Archaea, Bacteria and Eucarya in terms of small subunit ribosomal RNA characteristics. Syst Appl Microbiol 14, 305-310.

Woese, C. R. (1987). Bacterial Evolution. Microbiol Rev 51, 221-271. Woese, C. R., Gutell, R., Gupta, R. \& Noller, H. F. (1983). Detailed analysis of the higher order structure of $16 \mathrm{~S}$-like ribosomal ribonucleic acids. Microbiol Rev 47, 621-669.

Woese, C. R., Kandler, O. \& Wheelis, M. L. (1990). Towards a natural system for organisms: proposal for the domains Archaea, Bacteria and Eucarya. Proc Natl Acad Sci US A 87, 4576-4579. 